Dr. Aveling has made to Dr. Matthews Duncan's teaching. I would, however, first remark, that the outline Dr. Duncan gives of the point of an "ordinary uterine probe" shows a far different instrument to that which we are accustomed to use "down south." His, as he says, "has a wedge-shape of so large an angle as to destroy almost entirely any wedge-like action which it otherwise might possess :" whereas our ordinary uterine sound has an olive-shaped point, which presents even a far better wedge-shape than the outline Dr. M. Duncan has given "of an urethral bougie." Dr. Aveling has arranged his objections under five heads, so that their consideration will be facilitated by quoting them.

"I. The uterus is not a body rigidly fixed, but one which, under very slight mechanical influences, tumbles about hither and thither; and this extreme mobility renders it utterly impossible for an operator to be certain that he is applying the wedge-force of the bougie in a proper direction."

Doubtless, the uterus is a movable organ, but not in all directions equally so. There is a restraint in one direction which makes it quite possible for an operator to know whether he is applying force in the right direction. Though some of the ligaments of the uterus, as, e.g., the utero-sacral and the utero-vesical ligaments, may be comparatively weak, yet the vagina itself holds the uterus steady for us in the very direction we want, viz., opposite to the force applied. The way to force a sound without having the uterus tumbling "about hither and thither" is, when the point is passed into the uterine canal as far as the obstruction, to let the sound lie in the interspace between the knuckles of the first and second fingers, using it as a fulcrum, the point of the first finger resting simultaneously upon the lips of the uterus and the staff of the sound, so as to detect any real onward advance of the instrument, while the second finger is pressed backwards and downwards, rendering part of the posterior wall of the vagina tense, and so keeping the uterus steady. Of course we must premise that the operator does know the direction in which he is to push the dilator along the canal; for no one should try to forcibly extend the canal until he has first introduced a fine sound that he may learn the direction.

" 2 . The dilating action of a metal grazing along the mucous lining of the canal is objectionable and unnecessary, as it may be avoided by using tents and other dilating instruments.'

We want to avoid using tents where not actually necessary, as their retention renders septicremia possible. I doubt whether the word "grazing" is quite the right term by which to describe the passage of a perfectly smooth well-oiled metallic stem, however tightly it may fit.

" 3 . The uterus may be in a spongy and flaccid condition, capable of being bent upon itself by the pressure of the point of a bougie acting on either side. In such a case, the extreme liability of the bougie penetrating the side upon which it impinges is obvious."

In the condition thus described, it surely would not be advisable to attempt forcilll dilatation. A "spongy" uterus would need local bleeding and otherwise bracing up before it would be fit for such an operation.

"4. The cavity of the uterus varies in length, so as to make it difficult to determine whether the point of the bougie have arrived at the internal cervix or the fundus uteri. If it, by mistake, be 'urged through' the latter, serious conscquences might follow."

I suppose here "cervix" is a misprint for "os." Let us consider this case. The sound is arrested, say, at two inches and a quarter, is it stopped by narrowing of the internal os, or by the fundus uteri ? If by the former, a careful examination would reveal a very large and doubtless thickened cervix, with a long and probably indurated vaginal portion, and the rest of the uterus would be felt either per aldomen or be found pir vaginam to be flexed. Should we, however, meet with umbilical pain, a small thin or conical cervix, and perhaps be able to feel but little tissue between the point of the sound and the hand outside, we may conclude that we have reached the fundus, and that it would be unwise to proceed farther. Besides, if the uterus is so very movable, perhaps we might move it until one could feel the whole organ.

" 5. In narrow strictures a thin bougie must be used; and the more resisting the stricture and the thinner the bougie, the greater is the risk of the uterine walls being penetrated."

In these three last oljictions, reference has been made to perforation of the uterus. I should have almost thought that all were agreed that the uterine sound or probe should be held as lightly as any other probe, and nearly allowed to find its own way into the uterus. There is a great advantage in making the sound with a very small handle like a catheter, in order that it should not be held like an " uterine poker," as some have slightingly called it. I am aware that an uterus may be so diseased as to allow the passage of a sound through its walls with facility and without any bad result, but such a case would not be a subject for forcible dilatation.
The reason why dilatation of the cervix often fails and produces mischief is, that tents are used when the cervix is not in a fit state to receive them ; sufficient care not being taken to try to find out whether there is the least trace of deposit from any former inflammation, for such deposit is ever apt to become the seat of subsequent mischief.

Provided these precautions are taken, the method of dilatation usually pursued by my father (Dr. Protheroe Smith) seems to commend itsel as rational. He commences by slightly incising, with a single knife per speculum, the external os bilaterally, and this chiefly with the view to the relief gained by the loss of blood, the uterus being thereby rendered less liable to take on inflammation. Then, after a few days, when the uterus has been gradually accustomed to the introduction of the sound, he introduces his uterine dilator, which is like a lithotrite, and rather pointed, the blades being separable by a screw having an index to mark the degree of dilatation. This is to be used gradually - the separation of the blades being regulated by the pain experienced ; on pain being indicated, the blades are closed and the instrument withdrawn. This should be repeated, as it can be borne, until at last it will be found that the cervical canal has been well dilated. If desired, a small knife can now be passed up and the constriction of the internal os divided. After such dilatation, a metallic expanding intrauterine stem may be worn with but little inconvenience. The great object to be aimed at in the dilatation of the cervix uteri is that, the requisite dilatation once attained, the uterus should not easily return to its constricted state.

\section{POISONING BY CARBOLIC ACID.}

\section{BY DAVII) FERRIER, M.D.,} Professor of Forensic Medicine in King's College.

ON Friday, January 3 Ist, I was asked by my friend Dr. Saltern G. Litteljohn, to examine with him the body of a boy named John Winter, aged 7 , who was found, early the previous morning, lying on the floor of his dormitory in the Central London District School, Hanwell, in a moribund condition, and who died in the course of a few hours under what were considered very obscure nervous symptoms. The lad was of the strumous diathesis, with enlarged head, and had been occasionally ailing some time previously. These circumstances, with the state of coma in which he was found, led, in the absence of any other positive fact, to the supposition that the case was one of obscure cerebral disease suddenly manifesting itself. The results of the post mortem examination detailed below led me to inquire more fully into the circumstances under which he was found; and the following notes were furnished me by Dr. Litteljohn.

About four o'clock in the morning of Thursday, January 3 oth, the nurse in the ward was awakened by loud stertorous breathing; and, on rising to inquire into the cause, she found the lad. John Winter lying in an unconscious state on the floor of the dormitory, half way between his bed and the cupboard at the end of the ward. The nurse thought he had been seized with a fit, and at once put him to bed. Dr. Litteljohn arrived in the course of a few minutes, and found the boy in a state of complete stupor, with total muscular relaxation and anæsthesia. The breathing was stertorous; the pulse feeble and rapid, 160 in the minute. The temperature was greatly lowered; the pupils were strongly contracted; saliva flowed from the mouth. Without knowing anything further of the case, Dr. Litteljohn first administered an emetic of sulphate of zinc, and endeavoured to induce vomiting, but without success. Hot blankets were applied to the feet and abdomen to raise the temperature, and an injection containing brandy was given per antum, as the power of swallowing became lost. All efforts to rouse the boy proved unavailing. The respiration failed, the pulse became imperceptible, and death took place at I0.45 A.M., about seven hours after the symptoms were first observed.

On Friday, twenty-four hours after death, we made the post mortem examination. Cadaveric rigidity existed, but not to any marked degree. No traces of injury could be seen, nor were any marks about the mouth and lips perceptible at the time. On opening the head, the cerebral sinuses were found greatly distended with dark fluid blood, with here and there small soft coagula. All the cerebral vessels were in a similar state of congestion. There was a comparatively small amount of fluid in the subarachnoid space, and in both lateral ventricles; but, with the exception of slight thickening of the membranes at the base of the brain, nothing otherwise abnormal could be detected in the brain itself or in the medulla oblongata. During careful scrutiny, we perceived a faint but unusual odour; but it was not till the thorax and abdomen had been opened, when the same odour was intensified, that we at once identified it as the odour of the ordinary impure com- 
mercial carbolic acid. Our attention being drawn to this more particularly, we had no difficulty in detecting the odour, especially in the ventricles, and the nature of the case before us became manifest. There was general venous congestion in the thorax and abdomen, the blood being very dark and fluid. The lungs were congested and oedematous ; and emphysema, both vesicular and intercellular, was well marked; the visceral pleura being raised in bullæ in several places over both lungs. The heart was quite empty ; the left ventricle strongly contracted; the right more flaccid, but also empty. No coagula existed in the great vessels. The lungs, and the blood and fluid which escaped from them on section, exhaled the carbolic acid odour. Through a slight accident in removing the stomach, a small portion of its contents escaped into the pleural cavity. In these the odour of carbolic acid was most distinct. The mucous membrane of the mouth, throat, and œsophagus, was white, sodden, and corrugated, but not detached. The mucous membrane of the stomach, examined afterwards, was of the same character; at the cardiac end there was some injection, but no capillary hæmorrhage was observed. These membranes smelt distinctly of carbolic acid. The smell could also be perceived as far as the upper part of the jejunum, but not in the rest of the alimentary canal. The liver, spleen, and kidneys, were hyperæmic-all having a slight odour of carbolic acid-but the kidneys had a mixed odour of urine and carbolic acid. The bladder contained about eight ounces of urine, which when drawn off was observed to have a slight olive-greenish tint, and a peculiar mixed odour. It contained no albumen.

The appearances described, combined with the odour, were of themselves quite diagnostic of poisoning by carbolic acid ; but, as confirm. atory evidence, I applied, with the materials at my disposal, some tests to the urine and contents of the stomach, in a rough manner, reserving the rest for further analysis if necessary.

Bromine water (Landolt's test), applicable to the urine directly, was used, and a copious yellowish precipitate of tribromophenol was yielded by about a cubic centimetre of the urine. The amount of the precipitate was such as to indicate, without doubt, the abnormal existence of carbolic acid in the urine. Aware, however, of the statements of Städeler, Landolt, etc., that carbolic acid is a normal constituent of urine, and that in normal urine, in quantity about 500 cubic centimètres, a precipitate may be obtained of tribromophenol, or at least a substance which yields phenol when treated with sodium-amalgam, I reserved the urine for further investigation, more on chemical and physiological grounds than for confirmation of the fact of poisoning by carbolic acid. On examining the urine seven days afterwards (it having been kept in a corked bottle half full), I found that it had changed into a dark brown liquid, like the urine frequently observed when carbolic acid has been administered in small doses internally, or when carbolic acid lotions have been long applied externally. It had suffered little or no decomposition. This was a strong confirmation, if not demonstration, of the view that the dark colour of the urine observed under the conditions mentioned is due to oxidation-products of carbolic acid, and not to altered blood-colouring matter, as has been supposed by some. The oxidation had taken place outside the body, no doubt under the same conditions as lead to the urine being passed of that colour. This was interesting, as showing the passage of carbolic acid unchanged through the organism - a subject which has been investigated by Salkowski and others, and of interest in a therapeutical point of view.

In order to determine if any free carbolic acid still existed, I distilled the urine by itself, without the addition of sulphuric acid, in order to avoid such a fallacy as Hoppe-Seyler has pointed out-viz., that the action of sulphuric acid may develope phenol from indican, or some allied substance, existing normally in urine. The distillate yielded a distinct reaction with bromine water; thus indicating that the carbolic acid had passed into the urine unchanged, or at least partly so, and that the process of oxidation had gone on outside the body.

By distilling the liver and contents of the stomach with sulphuric acid, I obtained a distillate in each case giving the reaction, with Landolt's test applied to about a cubic centimètre of the liquid. Landolt's test is by far the most delicate for carbolic acid, in such small amount as can be obtained by distilling substances containing it themselves in such minute quantity. I could not obtain the reaction with perchloride of iron, or ammonia and chloride of lime, with such portions of the unconcentrated distillate as yielded Landolt's reaction distinctly. I may mention here, that the blue-colour reaction which is developed in very dilute solutions of carbolic acid by the successive action of ammonia and chloride of lime is one which requires considerable care in its application, and does not manifest itself speedily when performed in the ordinary manner; it may be obtained readily, in a a short time, by placing a few drops of the solution on a porcelain lid, adding a drop of ammonia, and the placing on the surface a small clot of chloride of lime. The blue colour rapidly appears round the particle of chloride of lime, and soon becomes intense and characteristic.

Dr. Litteljohn informs me that, in the course of another day after the post mortem examination, a roundish parched-like spot, different in colour from the surrounding skin, had developed itself on the lips. This was valuable evidence of the source of the poison. It seems that the boy had been given to pilfering from the cupboard in which the nurse kept some of her own things. At the time she had in this cupboard a pint bottle, containing a strong solution of commercial carbolic acid for scrubbing purposes. The mark on the lips indicated that the boy had put this bottle to his mouth, thinking it contained something to drink, and that, having discovered his mistake, he has endeavoured to make his way back to bed, but had fallen down before he had got more than half way. Without having made any quantita. tive analysis, I judged that the quantity swallowed could not have been large, but it would be impossible to state anything definite regarding it. Death must have taken place within eight hours.

\section{NOTES TOWARDS THE HISTORY OF THE MEDICAL STAFF OF THE ENGLISH ARMY PRIOR TO} THE ACCESSION OF THE TUDORS.*

\section{By W. R. E. SMART, C.B., M.D.,} Inspector-General, R.N.

[Conclzeded from page $14 \mathrm{I}$ of last mumber.]

THE next page of the history of the English army lies in the reign of Edward III, the glorious grandson of Edward I. It embraces the wars of that monarch for the crown of France, by claim through his mother as daughter of Philip IV, and is filled with the records of Crecy, Calais, and Poitiers, and of the great naval victories of Sluys and Winchelsea, but it closes with the surrender of all the hereditary possessions of the Plantagenets in France. In these wars the very principle of feudal service was undermined, and the army and navy of England first became "royal services" in the pay of the king, as it was not possible to carry on such wars on the feudal principle of forty days' service in the field.

The muster-roll of the great army with which King Edward invaded France in 1346 is extant ; but with regard to its medical staff it is silent, except that the "Welsh," or British, who appear therein for the first time as a distinct body of troops in the continental wars, under the banner of the Black Prince, had an attendant physician of their own race.

Froissart makes no mention of any distinguished surgeons, nor does he allude to any services of members of the medical profession. It is inconceivable, however, that so large an army, whose stay in France was protracted, and which was greatly harassed by sickness, could have been less considered and provided for in this particular than was the army of the king's grandfather in the invasion of Scotland, A.D. I300. It is more probable that the great barons who brought their contingents for the king's service, receiving the pay for their followers, had the engagement of surgeons, among others, in their own hands; and thus, as we know nothing of the economy of those separate contingents, we must ever remain in the dark concerning the medical affairs of the great army that won Crecy.

The age was one of general progress and of consolidation of Normans and British into the English nation, and yet there are no tangible proofs of progress in the manner in which the fighting men were cared for when wounded or sick. Our national records prove that the king esteemed very highly the medical services rendered to himself in England, and was bountiful in rewarding those who performed them, and this makes the silence of chroniclers on this point the more unaccountable.

The first half of the fourteenth century was the era of the moulding of our profession into its present form. Our universities were established and granting degrees in medicine. Physicians were men of such education as to make them masters of colleges and teachers of the natural sciences, and to lead to their employment on diplomatic missions which had been mainly the province of churchmen.

Gilbertus Anglicus had written his work on medicine, that proves him acquainted with the writiugs of the Greek and Arabian physicians, which he condensed before A.D. 1220 .

John Ardern, the first English writer on surgery, lived at Newark 1349 to 1370 , when he settled in London, obtaining celebrity in both

* Read before the Public Medicine Section at the Annual Meeting of the British Medical Association in Birmingham, August 1872 . 